\title{
Article \\ Effects of Integrated Indirect Forest Experience on Emotion, Fatigue, Stress, and Immune Function in Hemodialysis Patients
}

\author{
Hyoyoung Kang $\mathbb{D}$ and Youngran Chae * \\ Department of Nursing, Kangwon National University, Chuncheon 24341, Korea; sissy2@naver.com \\ * Correspondence: yrchae@kangwon.ac.kr
}

Citation: Kang, H.; Chae, Y. Effects of Integrated Indirect Forest Experience on Emotion, Fatigue, Stress, and Immune Function in Hemodialysis Patients. Int. J. Environ. Res. Public Health 2021, 18, 1701. https://doi.org/10.3390/ ijerph18041701

Received: 21 December 2020

Accepted: 7 February 2021

Published: 10 February 2021

Publisher's Note: MDPI stays neutral with regard to jurisdictional claims in published maps and institutional affiliations.

Copyright: (c) 2021 by the authors. Licensee MDPI, Basel, Switzerland. This article is an open access article distributed under the terms and conditions of the Creative Commons Attribution (CC BY) license (https:/ / creativecommons.org/licenses/by/ $4.0 /)$.

\begin{abstract}
Background: Most hemodialysis patients may experience physiological and psychological stress. Exposure to nature has been reported to reduce psychological and physiological stress levels and improve immune function. This study aimed to investigate psychological and physiological effects of integrated indirect forest experience on chronic renal failure patients undergoing hemodialysis. Methods: As a quasi-experiment, this study employed a nonequivalent control group, repeated measurements, and a non-synchronized design. In total, 54 participants were included: 26 and 28 patients in the experimental and control groups, respectively. During hemodialysis, five types of forest therapy stimuli (visual, auditory, olfactory, tactile, and motor) were applied 3 times per week for 4 weeks during 15 min sessions. Results: Positive, but not negative, emotion measures differed between the groups after the intervention. Fatigue and physiological stress levels were significantly reduced in the experimental group, whereas no significant difference was found between the groups with respect to measures of psychological stress. Activation of both the parasympathetic and sympathetic nervous systems was similar in both groups, as was the number of natural killer cells. Conclusion: Integrated indirect forest experience may help increase positive emotions and reduce fatigue and stress levels during hemodialysis in patients with chronic renal failure.
\end{abstract}

Keywords: hemodialysis; indirect forest experience; emotion; fatigue; stress; heart rate variability; natural killer cells

\section{Introduction}

Chronic renal failure is an irreversible disease associated with gradual loss of kidney function [1]. In Korea, affected patients tend to choose hemodialysis (81,760 (75.1\%) patients), rather than renal transplant or peritoneal dialysis [2]. Without a transplant, most hemodialysis patients continue to undergo dialysis for over 4-5 h, 3-4 times weekly, for the rest of their life [3].

During hemodialysis, patients may experience physiological and psychological stress due to restrictions that prevent them from maintaining their daily routines [4]. The primary factor that causes stress in patients is fatigue [5]. Seventy-nine percent of hemodialysis participants complain of fatigue [6], which tends to increase after hemodialysis [7]. Concurrently, psychological stress in hemodialysis patients tends to be caused by tensions provoked by dependence on hemodialysis machines [8], loss of pride, uncertainty about the future, and feelings of guilt toward family [9], among others. Indeed, previous studies have shown that stress levels in hemodialysis patients are as high as those in patients with terminal cancer [10]. Severe and prolonged stress response may lead to the suppression of the immune system function [11]. Therefore, it is critical to develop stress management interventions for hemodialysis patients.

Stress reduction theory has been proposed by Ulrich: it aims to explain how the natural environment reduces the human response to mental and physical stress, for example, during the sequential process of viewing nature scenes, which may influence one's emotions and behavior [12]. According to this theory, an individual exposed to visual 
stimuli associated with the natural environment is likely to experience immediate and general emotional and automatic behavioral response [12]. For example, if the observer is stressed, a view of nature can attract attention and block or reduce stressful thoughts, thus promoting psychophysiological recovery [13]. In line with this theory, forest therapy has been attracting attention, and some studies suggest that it promotes physical health and may strengthen the immune system [14], while others show that it may improve mental and physical health [15], affecting physiological and psychological parameters. Managed by the autonomic nervous system, heart rate variability (HRV) is a biomarker of stress [16-18]. Previous studies have indicated that forest therapy may activate the parasympathetic and inhibit the sympathetic nervous system responses [19,20]; moreover, it has also been shown to affect immune function [21], specifically, to increase the activity of natural killer cells (NK) [22].

Indirect forest experience involves providing forest-like stimuli to patients indoors [23]. Psychological and physiological stress levels have been shown to alleviate in response to just viewing nature scenes [24,25]; however, patients tend to prefer receiving both visual and auditory stimuli at the same time (e.g., seeing a nature view while listening to water sounds) [26]. Moreover, olfactory stimulation with wood-scented oil significantly increases parasympathetic activity [27]. Although few studies exist on tactile stimulation, touching wood with feet has been shown to have a positive impact on brain activity and to promote physiological relaxation [28]. In a study that applied an electric leg exercise machine to patients undergoing hemodialysis in a supine position, the patients' mental health index score increased significantly, which suggests that this could be a safe and effective intervention [29].

Recent studies of indirect forest experience mostly focused on healthy individuals [15,20,23], and few of such studies have been performed in a clinical context [30,31]. Studies of indirect forest experience that involve five senses are rare, despite evidence that this approach is more effective than that involving only one or two senses [32]. In fact, in a study of older adults, Park [33] reported that stimulating five senses might be more effective than stimulating only one or two of the senses in indirect forest therapy.

Hemodialysis patients have restricted access to nature due to their treatment and deconditioning schedule. Exposing patients to nature-associated sensory stimuli while they remain in a hospital environment may provide them with physiological and psychological benefits of forest therapy. This study aimed to verify the effects of integrated indirect forest experience on the measures of emotion, fatigue, and stress, HRV, and NK cells count in patients with chronic renal failure undergoing hemodialysis.

\section{Materials and Methods}

\subsection{Participants}

In this quasi-experimental study with a nonequivalent control group, repeated measurements, and a non-synchronized design, 130 patients with chronic renal failure undergoing hemodialysis at a designated unit of a medical clinic were selected using convenience sampling.

Using repeated measures analysis of variance (ANOVA) with $G^{*}$ Power 3.1 software [34], we determined that 52 individuals in total (26 per group) were required for the present study, given a significance level of 0.05 , an effect size of 0.18 [35], and a statistical power of 0.80. Accounting for possible dropouts, we included 64 (32 per group) participants. In the experimental group, 2 participants changed clinics, 1 withdrew, and 3 failed to meet the compliance rate of the experimental group, resulting in the final group size of 26. In the control group, 1 participant changed clinics, 1 experienced health deterioration, and 2 missed hemodialysis sessions, resulting in the final group size of 28. Overall, 54 participants were included in the study, and the dropout rate was $15.6 \%$. 


\subsection{Materials}

Demographic and clinical characteristics of interest included age, sex, marital status, education level, occupation, religion, cause of disease, period of hemodialysis, vascular state for hemodialysis, hemodialysis vessel location, hemoglobin, and albumin.

Emotion: The inventory of personal reactions developed by Zuckerman (ZIPERS) [36] was used to examine emotional reactions toward indirect forest environments. The scale included four items of positive affect, two items of attentiveness, with one item being a negative question to ensure faithful answers, three items of fear, one item of sadness, and two items of anger, totaling to five categories and twelve items (Table 1). Among the 12 items of ZIPERS, items \#1 to \#6 represented positive emotions and items \#7 to \#12 represented negative emotions [37]. Each question was measured using a 5-point scale (not at all: 0 points, very true: 5 points). The total score ranged from 0 to 30 points, with higher scores indicating that the individual had more positive and negative emotions. In our study, Cronbach's alpha values were 0.62 and 0.90 for the positive and negative emotion components respectively, with previously reported values ranging from 0.80 to 0.85 [36].

Table 1. Zuckerman inventory of personal reaction scale (ZIPERS) subclass and questions.

\begin{tabular}{|c|c|}
\hline Subclass & Questions \\
\hline Positive affect (4) & $\begin{array}{l}\text { I felt carefree or playful } \\
\text { I felt affectionate or warmhearted } \\
\text { I felt elated or pleased } \\
\text { I felt like acting friendly or affectionate }\end{array}$ \\
\hline Attentiveness (2) & $\begin{array}{l}\text { I felt attentive or in deep thought } \\
\text { I felt like getting out of this situation or avoiding it (reverse) }\end{array}$ \\
\hline Fear (3) & $\begin{array}{l}\text { My heart was beating fast } \\
\text { I was breathing fast } \\
\text { I felt fearful }\end{array}$ \\
\hline Sadness (1) & I felt sad \\
\hline Anger (2) & $\begin{array}{l}\text { I felt angry or defiant } \\
\text { I felt angry or acted aggressively }\end{array}$ \\
\hline
\end{tabular}

Fatigue: Fatigue was measured using a tool proposed by Lee et al. [38], and it was revised and updated by Kim [39]. Among 17 items, a single item was eliminated [40] as it was not suitable for the present study. This tool comprised a 12-item fatigue subscale (tired, sleepy, dull, drowsy, fatigued, worn out, moving my body, concentrating, carrying on a conversation, desire to lie down, exhausted, and keeping my eyes open) and a 4-item energy subscale (energetic, efficient, vigorous, and active). The total score ranged from 0 (not fatigued at all) to 160 (extremely fatigued) points, measured on a 10-point Likert scale. In our study, Cronbach's alpha was 0.83 , while the previously reported values ranged from 0.94 to 0.96 [38].

Stress: Stress levels were measured using a tool developed for hemodialysis patients by Kim [41], and it was revised and updated by Choi [42]. The tool includes 20 items in total, with physiological and psychological stress interrogated by a set of 10 questions each. Physiological stress included stress from physical symptoms such as muscle cramps, fatigue, skin itching, joint discomfort, sleep disturbances, and decreased concentration and memory. Psychological stress included stress caused by uncertain future, changes in appearance, discomfort in daily life due to hemodialysis, difficulties in work life, economic burden, feeling guilty about the roles of family members in care, and anxiety during hemodialysis. Using 4-point Likert scales, the stress scores yielded by the tool ranged from 10 (not serious at all) to 40 (extremely serious) points, with higher scores indicating that the individual was more stressed. In our study, Cronbach's alpha was 0.86 for both physiological and psychological stress levels. In Choi's study, Cronbach's alpha for physiological stress and psychological stress was 0.86 and 0.79 , respectively [42]. 
To assess the physiological indicator of stress, we assessed minimum changes in heart rate using an HRV meter (Wise-8000T, MooYoo Instrument, Seongnam, Korea), and autonomic nerve responses were observed. HRV measured parameters such as sympathetic nervous system activity (low frequency) and parasympathetic nervous activity (high frequency). The normal range of the sympathetic and parasympathetic nervous system activity is within low $(0.04-0.15 \mathrm{~Hz})$ and high $(0.15-0.4 \mathrm{~Hz})$ frequency values, with the corresponding power spectrum of 5.9-8.0 and 3.8-7.0, respectively. The examination of HRV was performed during the dialysis session and after using the electric exercise machine.

NK cells: The immune function was measured using flow cytometry to assess the NK cell (CD16 + CD56) levels. To this end, $3 \mathrm{~mL}$ of blood was collected in ethylenediaminetetraacetic acid (EDTA) tubes and sent to the Seegene medical foundation laboratory. The instruments for blood sampling (blood collection syringes, sampling tubes, etc.) were disposable.

\subsection{Indirect Forest Stimulation}

We used visual, auditory, olfactory, tactile, and motor stimulation for all participants. For visual and auditory stimulation, a TV screen was used to play videos and sounds of nature. The videos included a variety of forests, including trees and water. Olfactory stimulation was concurrently provided by placing a cotton pad with drops of cypress oil on the right shoulder of each participant. For tactile stimulation, we simulated walking on wood using an electric leg exercise machine set up with paulownia wood. The speed of the electric leg exercise machine can be adjusted to 15 steps. Based on a preliminary study, it was applied by setting the step at 2 to 3 so that it would not be a burden to the patient during hemodialysis (Table 2).

Table 2. Five types of indirect forest experience.

\begin{tabular}{ll}
\hline \multicolumn{1}{c}{ Categories } & \multicolumn{1}{c}{ Contents } \\
\hline Visual stimuli & Nature videos provided by TV monitor \\
Auditory stimuli & Sounds of nature (water, wind, insects, birds, etc.) \\
Olfactory stimuli & Cotton pad with drops of cypress oil placed \\
Tactile stimuli & Paulownia scaffold applied \\
Motor stimuli & Electric leg exercise machine for bed applied in 2 to 3 steps \\
\hline
\end{tabular}

These sessions were delivered during hemodialysis. In total, 13 sessions were performed, including three 15 min sessions per week over 4 weeks, as determined by the hemodialysis schedule. The program started $3 \mathrm{~h}$ after hemodialysis began, as patients were expected to have the highest levels of stress, fatigue, and other physiological changes between 3 and $4 \mathrm{~h}$ after hemodialysis start [43]. The program was performed under the supervision of healthcare staff.

All interventional tools in contact with the study participants were disinfected before and after application. The researcher strictly followed hand hygiene using a disinfectant before and after the intervention was applied to the participants.

\subsection{Data Collection}

This study was approved by the Human Clinical Research Ethics Committee of Kangwon National University (Approval No.: KWNUIRB-2019-12-003-001). Informed consent was obtained from the participants, and the study adhered to the Declaration of Helsinki.

Data collection took place between 13 January and 31 March 2020. Levels of emotion, fatigue, stress, and HRV of the patients in the control group were evaluated at baseline and during weeks 2 and 4 . Levels of emotion, fatigue, and stress were measured by selfreport. When measuring HRV, the participants were instructed to be still. Subsequently, the program was delivered to the experimental group, where the same schedule was followed. Levels of NK cells were measured at baseline and in week 4 in both groups. 


\subsection{Statistical Analysis}

Data analysis was performed using SPSS software 24.0 (IBM Corporation, Armonk, NY, USA). Homogeneity between experimental and control groups was examined using the independent $t$-test, $\chi^{2}$ test, and Fisher's exact test. To determine program effects, a dependent variable that met the normality of distribution assumption (measure of fatigue) was tested using the repeated measures ANOVA. Other dependent variables that did not meet the normality of distribution assumption (measures of positive emotions, negative emotions, physiological stress, psychological stress, parasympathetic nervous activity, and sympathetic nervous activity) were analyzed using the generalized estimate equation. Finally, between-group differences in program effects on NK cell levels were analyzed using the independent $t$-test.

\section{Results}

\subsection{Demographic and Clinical Characteristics of the Participants}

The mean age of the experimental group was $60.35( \pm 2.37)$ years old and the mean age of the control group was $56.89( \pm 2.68)$ years, but there was no significant difference. Also, there was no significant between-group difference in demographic characteristics such as gender, marital status, education, etc. Diabetes was the most common comorbid disease in the two groups. There was no difference between the two groups in clinical characteristics including comorbidity, period of hemodialysis, hemoglobin, and albumin levels in the blood (Table 3).

Table 3. Demographic and clinical characteristics of the groups $(n=54)$.

\begin{tabular}{|c|c|c|c|c|c|}
\hline \multirow{2}{*}{ Characteristics } & \multirow{2}{*}{ Categories } & \multirow{2}{*}{$\begin{array}{c}\text { Exp. }(n=26) \\
\text { Mean } \pm \text { SD } / n(\%)\end{array}$} & \multirow{2}{*}{$\begin{array}{c}\text { Cont. }(n=28) \\
\text { Mean } \pm S D / n(\%)\end{array}$} & \multirow{2}{*}{$\chi^{2}$ or $\mathrm{z}$} & \multirow{2}{*}{$p$} \\
\hline & & & & & \\
\hline Age (year) & & $60.35 \pm 2.37$ & $56.89 \pm 2.68$ & 27.63 & 0.640 \\
\hline \multirow[t]{2}{*}{ Gender } & Male & $18(69.2)$ & $22(78.6)$ & 0.61 & 0.434 \\
\hline & Female & $8(30.8)$ & $6(21.4)$ & & \\
\hline \multirow[t]{2}{*}{ Marital status } & Married & $23(88.5)$ & $22(78.6)$ & 0.95 & $0.470^{+}$ \\
\hline & Single & $3(11.5)$ & $6(21.4)$ & & \\
\hline \multirow[t]{3}{*}{ Education } & $<$ Middle & $8(30.8)$ & $6(21.4)$ & 0.79 & 0.675 \\
\hline & High & $7(26.9)$ & $10(35.7)$ & & \\
\hline & University & $11(42.3)$ & $12(42.9)$ & & \\
\hline \multirow[t]{2}{*}{ Occupation } & Yes & $12(46.2)$ & $11(39.3)$ & 0.26 & 0.610 \\
\hline & No & $14(53.8)$ & $18(60.7)$ & & \\
\hline \multirow[t]{2}{*}{ Religion } & Yes & $16(61.5)$ & $18(64.3)$ & 0.04 & 0.835 \\
\hline & No & $10(38.5)$ & $10(35.7)$ & & \\
\hline \multirow[t]{3}{*}{ Comorbidity } & Diabetes & $12(46.2)$ & $10(35.7)$ & 1.25 & 0.535 \\
\hline & Hypertension & $9(34.6)$ & $9(32.1)$ & & \\
\hline & etc. & $5(19.2)$ & $9(32.1)$ & & \\
\hline \multirow{2}{*}{ Period of hemodialysis (year) } & $<5$ & $16(61.5)$ & $14(50.0)$ & 0.73 & 0.394 \\
\hline & $\geq 5$ & $10(38.5)$ & $14(50.0)$ & & \\
\hline \multirow[t]{2}{*}{ Vascular state for hemodialysis } & Fistula & $23(88.5)$ & $25(89.3)$ & 0.01 & $>0.999^{+}$ \\
\hline & Graft & $3(11.5)$ & $3(10.7)$ & & \\
\hline \multirow[t]{2}{*}{ Hemodialysis vessel location } & Upper arm & $9(34.6)$ & $7(25.0)$ & 0.60 & 0.439 \\
\hline & Forearm & $17(65.4)$ & $21(75.0)$ & & \\
\hline Hemoglobin $(\mathrm{g} / \mathrm{dl})$ & & $10.77 \pm 1.19$ & $10.73 \pm 0.81$ & 30.84 & 0.324 \\
\hline Albumin (g/dl) & & $4.02 \pm 0.21$ & $4.00 \pm 0.33$ & 12.50 & 0.406 \\
\hline
\end{tabular}


Furthermore, the results of homogeneity tests for participants' positive and negative emotion, fatigue, physiological and psychological stress, activation of sympathetic and parasympathetic nervous systems, and NK cell levels showed no significant difference between the groups at baseline (Table 4).

Table 4. Values of dependent variables for the groups $(n=54)$.

\begin{tabular}{|c|c|c|c|c|c|}
\hline & \multirow{2}{*}{ Variables } & \multirow{2}{*}{$\begin{array}{l}\text { Exp. }(n=26) \\
\text { Mean } \pm \text { SD }\end{array}$} & \multirow{2}{*}{$\begin{array}{c}\text { Cont. }(n=28) \\
\text { Mean } \pm \text { SD }\end{array}$} & \multirow{2}{*}{$\mathbf{t}$} & \multirow{2}{*}{$p$} \\
\hline & & & & & \\
\hline \multirow[t]{2}{*}{ Emotion } & Positive emotion & $19.46 \pm 6.24$ & $18.82 \pm 6.15$ & -0.38 & 0.706 \\
\hline & Negative emotion & $4.89 \pm 7.80$ & $4.36 \pm 4.79$ & -0.30 & 0.764 \\
\hline Fatigue & & $63.62 \pm 28.14$ & $62.39 \pm 27.58$ & -0.16 & 0.873 \\
\hline \multirow[t]{2}{*}{ Stress } & Physiological stress & $18.19 \pm 5.84$ & $18.57 \pm 5.74$ & 0.24 & 0.811 \\
\hline & Psychological stress & $21.85 \pm 7.42$ & $21.14 \pm 5.90$ & -0.39 & 0.701 \\
\hline \multirow[t]{2}{*}{ HRV } & High frequency (HF) & $6.48 \pm 0.71$ & $6.45 \pm 0.96$ & -0.15 & 0.883 \\
\hline & Low frequency (LF) & $6.76 \pm 0.34$ & $6.72 \pm 0.54$ & -0.32 & 0.747 \\
\hline NK cells (\%) & CD16 + CD56 & $11.80 \pm 6.64$ & $14.24 \pm 9.82$ & 1.06 & 0.295 \\
\hline
\end{tabular}

Cont. = control group; Exp. = experimental group; $\mathrm{HRV}=$ heart rate variability; $\mathrm{NK}$ cells = natural killer cells; $\mathrm{SD}=$ standard deviation .

\subsection{Effects of Indirect Forest Experience}

For measures of positive emotion, the interaction between group and measurement time was significantly different $\left(\chi^{2}=7.26, p=0.027\right)$ (Figure 1a), whereas, for measures of negative emotion, there was no significant difference in this interaction $\left(\chi^{2}=3.63\right.$, $p=0.163$ ) (Table 5). Similarly, for measures of fatigue, there was a significant interaction between group and measurement time $(\mathrm{F}=3.75, p=0.027)$ (Figure $1 \mathrm{~b})$. There was a significant difference in interaction between group and measurement time for the measures of physiological stress $\left(\chi^{2}=9.60, p=0.008\right)$ (Figure $\left.1 c\right)$, whereas no such difference was observed for the measures of psychological stress $\left(\chi^{2}=0.84, p=0.657\right)$. There was also no significant difference in interaction between group and measurement time for the activation of either parasympathetic $\left(\chi^{2}=4.92, p=0.085\right)$ or sympathetic $\left(\chi^{2}=3.34, p=0.189\right)$ nervous system (Table 5). The difference in the number of NK cells between the groups was not statistically significant $(t=0.45, p=0.655)$ (Table 6$)$.

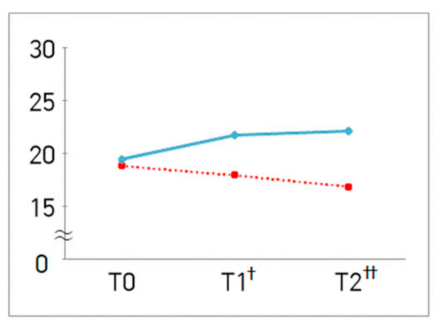

(a)

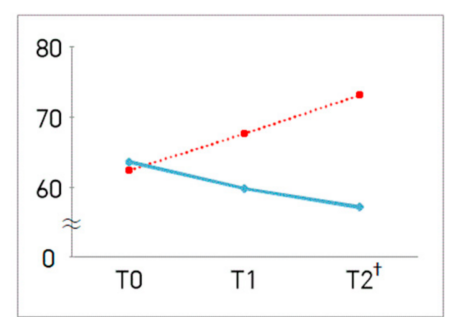

(b)

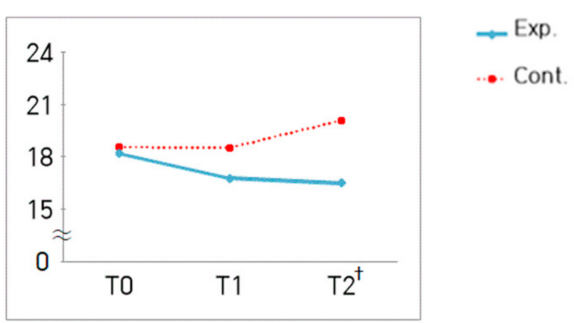

(c)

Figure 1. Changes to the measures of positive emotion (a), fatigue (b), and physiological stress (c) in both groups. $\mathrm{T} 0=$ baseline assessment; $\mathrm{T} 1=2$ nd week of the program; $\mathrm{T} 2=4$ th week of the program; ${ }^{+} p<0.05,{ }^{++} p<0.01$ indicates group differences by time point. 
Table 5. Effect of indirect forest experience on emotion, fatigue, stress, and HRV ( $n=54)$.

\begin{tabular}{|c|c|c|c|c|c|c|c|}
\hline & \multirow[t]{2}{*}{ Variables } & & Exp. $(n=26)$ & $\begin{array}{c}\text { Cont. }(n= \\
\text { 28) }\end{array}$ & \multirow[t]{2}{*}{ Source } & \multirow[t]{2}{*}{$F$ or $\chi^{2}$} & \multirow[t]{2}{*}{$p$} \\
\hline & & & Mean \pm SD & Mean \pm SD & & & \\
\hline \multirow{6}{*}{ Emotion } & \multirow{3}{*}{ Positive emotion } & T0 & $19.46 \pm 6.24$ & $18.82 \pm 6.15$ & Group & 5.74 & 0.017 \\
\hline & & $\mathrm{T} 1$ & $21.73 \pm 6.02$ & $17.93 \pm 6.06$ & Time & 0.87 & 0.648 \\
\hline & & $\mathrm{T} 2$ & $22.12 \pm 5.19$ & $16.86 \pm 5.84$ & Group-by -time interaction & 7.26 & $0.027^{\dagger}$ \\
\hline & \multirow{3}{*}{ Negative emotion } & T0 & $4.89 \pm 7.80$ & $4.36 \pm 4.79$ & Group & 2.12 & 0.145 \\
\hline & & $\mathrm{T} 1$ & $3.73 \pm 6.42$ & $4.61 \pm 5.38$ & Time & 0.22 & 0.898 \\
\hline & & $\mathrm{T} 2$ & $3.54 \pm 5.44$ & $5.68 \pm 6.42$ & Group-by -time interaction & 3.63 & $0.163^{\dagger}$ \\
\hline \multirow{3}{*}{ Fatigue } & & T0 & $63.62 \pm 28.14$ & $62.39 \pm 27.58$ & Group & 1.35 & 0.251 \\
\hline & & $\mathrm{T} 1$ & $59.81 \pm 22.07$ & $67.61 \pm 27.80$ & Time & 0.24 & 0.788 \\
\hline & & $\mathrm{T} 2$ & $57.15 \pm 25.63$ & $73.11 \pm 31.04$ & Group-by -time interaction & 3.75 & 0.027 \\
\hline \multirow{6}{*}{ Stress } & \multirow{3}{*}{$\begin{array}{l}\text { Physiological } \\
\text { stress }\end{array}$} & T0 & $18.19 \pm 5.84$ & $18.57 \pm 5.74$ & Group & 1.87 & 0.171 \\
\hline & & $\mathrm{T} 1$ & $16.77 \pm 5.54$ & $18.54 \pm 5.20$ & Time & 2.97 & 0.227 \\
\hline & & $\mathrm{T} 2$ & $16.50 \pm 5.18$ & $20.11 \pm 6.46$ & Group-by -time interaction & 9.60 & $0.008^{+}$ \\
\hline & \multirow{3}{*}{$\begin{array}{l}\text { Psychological } \\
\text { stress }\end{array}$} & T0 & $21.85 \pm 7.42$ & $21.14 \pm 5.90$ & Group & 0.30 & 0.584 \\
\hline & & $\mathrm{T} 1$ & $21.58 \pm 5.99$ & $21.11 \pm 6.29$ & Time & 0.35 & 0.838 \\
\hline & & $\mathrm{T} 2$ & $21.85 \pm 6.65$ & $20.39 \pm 6.81$ & Group-by -time interaction & 0.84 & $0.657^{+}$ \\
\hline \multirow{6}{*}{ HRV } & \multirow{3}{*}{ High frequency } & T0 & $6.48 \pm 0.71$ & $6.45 \pm 0.96$ & Group & 1.26 & 0.261 \\
\hline & & $\mathrm{T} 1$ & $6.94 \pm 1.09$ & $6.41 \pm 0.90$ & Time & 5.12 & 0.077 \\
\hline & & $\mathrm{T} 2$ & $6.55 \pm 0.95$ & $6.36 \pm 0.94$ & Group-by -time interaction & 4.92 & $0.085^{\dagger}$ \\
\hline & \multirow{3}{*}{ Low frequency } & T0 & $6.76 \pm 0.34$ & $6.72 \pm 0.54$ & Group & 0.81 & 0.368 \\
\hline & & $\mathrm{T} 1$ & $6.94 \pm 0.49$ & $6.73 \pm 0.51$ & Time & 3.30 & 0.192 \\
\hline & & $\mathrm{T} 2$ & $6.79 \pm 0.46$ & $6.73 \pm 0.53$ & Group-by -time interaction & 3.34 & $0.189^{+}$ \\
\hline
\end{tabular}

Cont. = control group; Exp. = experimental group; $\mathrm{HRV}=$ heart rate variability; $\mathrm{SD}=$ standard deviation; $\mathrm{T} 0$ = baseline assessment; $\mathrm{T} 1=2$ nd week of the program; $\mathrm{T} 2=4$ th week of the program; ${ }^{\dagger}$ generalized estimate equation.

Table 6. Effect of indirect forest stimulation on NK cell levels $(n=54)$.

\begin{tabular}{cccccc}
\hline \multirow{2}{*}{ Variables } & \multirow{2}{*}{ Group } & Pretest & Posttest & Mean Difference & \multirow{2}{*}{$\mathbf{t}$} \\
\cline { 3 - 5 } & & Mean \pm SD & Mean \pm SD & Mean \pm SD & \\
\hline \multirow{2}{*}{ NK cells (\%) } & Exp. $(n=26)$ & $11.80 \pm 6.64$ & $11.18 \pm 5.94$ & $-0.62 \pm 2.09$ & 0.45 \\
& Cont. $(n=28)$ & $14.24 \pm 9.82$ & $13.21 \pm 8.82$ & $-1.02 \pm 4.09$ & 0.655 \\
\hline
\end{tabular}

Cont. = control group; Exp. $=$ experimental group; NK cells = natural killer cells; $\mathrm{SD}=$ standard deviation .

\section{Discussion}

This study aimed to identify the psychological and physiological effects of an integrated indirect forest experience on hemodialysis patients' measures of emotion, fatigue, stress, and immune function. In the present study, indirect forest experience simultaneously stimulated five senses in patients undergoing hemodialysis, providing a simulation of outdoor experiences to individuals needing to remain in a hospital.

In our study, the measures of positive emotion increased after integrated indirect forest experience, and these changes were statistically significant. Previously, Hwang and Park [44] presented a slideshow of nature-related images to college students and found significant changes in their emotional states. Yi [45] compared urban views and nature views to establish which group of images may perform better at triggering positive emotions. In addition, Lee [37] suggested that individuals would be positively impacted if they felt the environment would give them positive effects. To summarize, integrated indirect forest experience could be applied to patients who experience emotional distress due to hemodialysis to increase their positive emotion. 
The impact of indirect forest experience on decreasing levels of fatigue has been previously reported in several studies [39,46,47]. Park [48] found psychological changes in college students exposed to the views of forests, and Jeon [23] reported that indirect forest experience may reduce the levels of tiredness. In our study, fatigue was significantly reduced in the experimental group compared to that in the control group. Hemodialysis patients are likely to experience high levels of fatigue, and indirect forest experience may be an effective fatigue management tool, provided it is continuously applied in a clinical setting.

In this study, physiological stress levels in the experimental group were significantly reduced compared those in the control group. However, psychological stress measures were not influenced by indirect forest experience. Hwang and Park's [44] study of indirect forest visual stimulation in college students as well as that by Yi et al. [45] reported significant results. In both studies, stress was significantly reduced by indirect forest experience. Since the participants of our study were patients with chronic renal failure, it is expected that there will be differences in psychological stress among university students. In particular, in the present study, the levels of psychological stress were higher than those of physiological stress, and this finding is consistent with that of Kim and Yang's [4] studies, whereby hemodialysis patients had high levels of psychosocial stress.

In the present study, there was no significant difference in either parasympathetic or sympathetic activity between pre- and post-intervention, as measured by HRV. Previously, Alvarsson et al. [49] reported that parasympathetic activity was not influenced by auditory stimulation with forest-associated sounds. However, Igarashi et al. [50] and Ikei et al. [51] have shown that parasympathetic activity was affected by olfactory and tactile stimulation respectively, resulting in physiological relaxation. A study by Jo et al. [52] has shown a significant decrease in stress levels as a result of decreased activation of the sympathetic nervous system. Considering the discrepancies in previous study findings, further research is required to determine the effect of indirect forest therapy types on nervous system activity. The reason why it is not significant in HRV may be related to an abnormal autonomic function. The majority of patients receiving hemodialysis have diabetes. One of the most overlooked serious complications of diabetes is cardiovascular autonomic neuropathy. In addition, if blood sugar is not controlled, HRV may be low owing to abnormal autonomic function [53]. In our study, about $40 \%$ of the participants had diabetes. Playing a key part in the immune system, NK cells are sensitive to stress [21], and higher levels of stress may reduce the activity of NK cells [54]. In our study, integrated indirect forest experience did not affect NK cell levels. This result was different from that of a previous study, which reported higher levels of NK cell activation in a forest meditation group than in the control group [22]. In addition, a 12-week high-intensity forest walking intervention has been previously reported to significantly increase the number of NK cells [55]. A study that applied a three-day bamboo forest therapy in male students also reported that their NK cell levels increased following this intervention [56]. Since our study applied indirect forest experience for 4 weeks, its effects are likely to be different from those previously reported. Given that NK cells activation in hemodialysis patients tends to be lower than that in healthy individuals [57], it is advisable to apply the present program over a longer period and to re-examine its effect on immunity. There are many confounding factors, such as the filter type of the hemodialysis machine [58] and the period of dialysis [59], which might influence the NK cell levels in the dialysis population. Further study should be conducted considering these confounding factors to improve immune function by applying forest experience in hemodialysis patients.

Age and education level are factors affecting the needs of hemodialysis patients [60]. Younger people need extensive psychological assistance to cope with negative emotion related to the disease. Additionally, young hemodialysis patients complained of more lack of energy, mobility limitations, and sleep disturbances than elderly hemodialysis patients [61]. Therefore, indirect forest experience may be recommended to young patients during hemodialysis to improve emotion, fatigue, and stress. The participants of this 
study were relatively young, with an average age of 58 years, and they had a high level of education, so they actively participated in indirect forest experience. With the active participation of the experimental group, positive emotion, fatigue, and physiological stress steadily improved over the second and fourth weeks of intervention, whereas the values of the control group appeared to be unchanged or worsened. Furthermore, participants in the experimental group reported that the program helped them feel like the hemodialysis session went faster than usual, and they were satisfied with the experience of "being in nature." Because most of the patients have to undergo hemodialysis for a lifetime, indirect forest experience can be recommended as an active strategy to improve their positive emotion, fatigue, and physiological stress.

This study had several limitations. First, it was difficult to control the impact of other environmental conditions, including the sounds of hemodialysis machines and other medical equipment, which may have affected the presented findings. Second, the participants were not randomly assigned to the experimental and control groups. Randomized controlled trials should be conducted in the future. Third, hemodialysis patients find it difficult to remain still while undergoing hemodialysis, resulting in movements that may have influenced the HRV values. Fourth, immune function was measured with a single index, specifically, NK cell levels. Future studies should use other indicators to examine the impact of indirect forest therapy on the immune function.

\section{Conclusions}

Indirect forest experience may promote positive emotions and reduce the levels of fatigue and stress in patients undergoing hemodialysis. This finding suggests that indirect forest experience may be useful to patients undergoing hemodialysis and those undergoing other forms of long-term treatment, for example, chemotherapy. This intervention may also help patients relax and rest during their treatment.

Author Contributions: H.K. was responsible for writing the whole passage. Y.C. was responsible for checking and revision. Both authors have read and agreed to the published version of the manuscript.

Funding: This work was supported by the National Research Foundation of Korea (NRF) grant funded by the Korea government (MSIT) (NRF-2019R1F1A1060253).

Institutional Review Board Statement: This study was approved by the Human Clinical Research Ethics Committee of Kangwon National University (Approval No.: KWNUIRB-2019-12-003-001).

Informed Consent Statement: Informed consent was obtained from all subjects involved in the study.

Data Availability Statement: Not applicable.

Acknowledgments: This study is a revision of the first author's doctoral dissertation from Kangwon National University.

Conflicts of Interest: The authors declare no competing interests.

\section{References}

1. Black, J.M.; Hawks, J.H. Medical-Surgical Nursing-Clinical Management for Positive Outcomes, 7th ed.; Elsevier Saunders: Philadelphia, PA, USA, 2005.

2. Korean Society of Nephrology. Current Status of Renal Replacement Therapy in Korea. Available online: http:/ /www.ksn.or.kr/ rang_board/inc/download.php?nocount=1\&code=sinchart\&num=2197 (accessed on 14 December 2020).

3. Kim, H. Special feature: Terminal renal failure. J. Kidney Health. 2006, 10, 4-7.

4. Kim, S.Y.; Yang, J.H. Factors influencing the stress of patients on hemodialysis. J. Korean Acad. Soc. Nurs. Educ. 2015, 21, 340-349. [CrossRef]

5. Harwood, L.; Wilson, B.; Locking-Cusolito, H.; Sontrop, J.; Spittal, J. Stressors and coping in individuals with chronic kidney disease. Nephrol. Nurs. J. 2009, 36, 265-276.

6. Parfrey, P.S.; Vavasour, H.M.; Henry, S.; Bullock, M.; Gault, M.H. Clinical features and severity of nonspecific symptoms in dialysis patients. Nephron 1988, 50, 121-128. [CrossRef] [PubMed] 
7. Han, S.J.; Kim, H.W. Influencing factors on post-dialysis fatigue in hemodialysis patients. Adv. Sci. Technol. 2016, 128, 131-139. [CrossRef]

8. Bae, Y.H.; Lee, K.W.; Yeom, H.A. The effectiveness of stress intervention program for hemodialysis patients in Korea: A meta-analysis. J. Korea Converg. Soc. 2020, 11, 361-373. [CrossRef]

9. Theofilou, P. Self-esteem in Greek dialysis patients: The contribution of health locus of control. Iran. J. Kidney Dis. 2012, 6, 136-140.

10. Koh, K.B.; Han, D.S. Coping strategy of patients with end stage renal disease on long-term hemodialysis. J. Korean Neuropsychiatr. Assoc. 1991, 30, 358-365.

11. Koh, K.B. Stress and Immunity. Korean J. Stress Res. 2008, 16, 151-159.

12. Ulrich, R.S. Aesthetic and affective response to natural environment. In Behavior and the Natural Environment; Human Behavior and Environment (Advances in Theory and Research); Altman, I., Wohlwill, J.F., Eds.; Springer: Boston, MA, USA, 1983; Volume 6, pp. 85-125. [CrossRef]

13. Ulrich, R.S. Visual Landscapes and Psychological Well-Being. Landscape Res. 1979, 4, 17-23. [CrossRef]

14. Shin, C.S.; Yeon, P.S.; Jo, M.N.; Kim, J.Y. Effects of forest healing activity on women's menopausal symptoms and mental health recovery. J. People Plants Environ. 2015, 18, 319-325. [CrossRef]

15. Lee, J.W.; Yeon, P.S.; Park, S.H.; Kang, J.W. Effects of forest therapy programs on the stress and emotional change of emotional labor Workers. J. Korean Inst. For. Recreat. 2018, 22, 15-22. [CrossRef]

16. Kim, H.G.; Cheon, E.J.; Bai, D.S.; Lee, Y.H.; Koo, B.H. Stress and heart rate variability: A Meta-analysis and review of the literature. Psychiatry Investig. 2018, 5, 235-245. [CrossRef]

17. Sara, R.H.; Hugo, M.L.V.; Alejandro, G.G.; Juan Ricardo, L.T. Heart rate variability as psychophysiological stress indicator In Mexican college volleyball players. Med. Sci. Sports Exerc. 2020, 52, 464. [CrossRef]

18. Michels, N.; Sioen, I.; Clays, E.; De Buyzere, M.; Ahrens, W.; Huybrechts, I.; Vanaelst, B.; de Henauw, S. Children's heart rate variability as stress indicator: Association with reported stress and cortisol. Biol. Psychol. 2013, 94, 433-440. [CrossRef]

19. Eom, P.D.; Whang, M.C. Effects of viewing environments of valley, forest road, and city on emotional state based on autonomic nervous system. J. Korean Inst. For. Recreat. 2015, 19, 1-12. [CrossRef]

20. Song, C.; Ikei, H.; Kagawa, T.; Miyazaki, Y. Effects of walking in a forest on young women. Int. J. Environ. Res. Public Health 2019, 16, 229. [CrossRef]

21. Delahanty, D.L.; Dougall, A.L.; Schmitz, J.B.; Hawken, L.; Trakowski, J.H.; Jenkins, F.J.; Baum, A. Time course of natural killer cell activity and lymphocyte proliferation in response to two acute stressors in healthy men. J. Health Psychol. 1996, 15, 48-55. [CrossRef]

22. Yang, E.S.; Seo, S.H.; Jeong, K.S.; Yoon, H.R.; Lee, D.H.; Hwang, B.G. The effects of short-term meditation and walking exercise in a forest on blood pressure, heart rate, NK-cell and POMS. A. J. Kinesiol. 2011, 13, 31-40.

23. Jeon, J.Y.; Shin, C.S. Effects of indirect forest experience on human psychology. Korean J. Environ. Ecol. 2017, 31, 420-427. [CrossRef]

24. Ulrich, R.S.; Simons, R.F.; Losito, B.D.; Fiorito, E.; Miles, M.A.; Zelson, M. Stress recovery during exposure to natural and urban environments. J. Environ. Psychol. 1991, 11, 201-230. [CrossRef]

25. Parsons, R.; Tassinary, L.G.; Ulrich, R.S.; Hebl, M.R.; Grossman-Alexander, M. The view from the Road: Implications for stress recovery and immunization. J. Environ. Psychol. 1998, 18, 113-140. [CrossRef]

26. Seo, J.H.; Sung, M.S. The impact of soundscape in landscape preference. J. Korean Inst. Lands. Archit. 2001, $29,10-18$.

27. Ikei, H.; Song, C.; Miyazaki, Y. Physiological effect of olfactory stimulation by Hinoki cypress (Chamaecyparis obtusa) leaf oil. J. Physiol. Anthropol. 2015, 34, 44. [CrossRef]

28. Ikei, H.; Song, C.; Miyazaki, Y. Physiological effects of touching the wood of Hinoki Cypress (Chamaecyparis obtusa) with the Soles of the Feet. Int. J. Environ. Res. Public Health 2018, 15, 2135. [CrossRef] [PubMed]

29. Kim, S.K. Effects of cycle ergometer exercise program during hemodialysis on hemodialysis patients' appropriateness for dialysis, fitness and health-related quality of life. Korean Soc. Adult Nurs. Conf. 2016, 11, 161-162.

30. Ochiai, H.; Song, C.; Ikei, H.; Imai, M.; Miyazaki, Y. Effects of visual stimulation with bonsai trees on adult male patients with spinal cord injury. Int. J. Environ. Res. Public Health 2017, 14, 1017. [CrossRef]

31. Song, C.; Ikei, H.; Nara, M.; Takayama, D.; Miyazaki, Y. Physiological effects of viewing bonsai in elderly patients undergoing rehabilitation. Int. J. Environ. Res. Public Health 2018, 15, 2635. [CrossRef]

32. Lee, J.H. A case study of the response to severe bed ridden disabilities applied horticultural therapy program of stimulation five senses. Master's Thesis, Dankook University, Seoul, Korea, 2009.

33. Park, G.H.; Shin, C.S.; Hahn, Y.S. Effects of indirect experience of forest healing factors on stress reduction, self-esteem and social connectedness improvements in the elderly participating in horticultural activities program. J. People Plants Environ. 2018, 21, 411-421. [CrossRef]

34. Faul, F.; Erdfelder, E.; Buchner, A.; Lang, A.G. Statistical power analyses using G*power 3.1: Tests for correlation and regression analyses. Behav. Res. Methods. 2009, 41, 1149-1160. [CrossRef]

35. Cho, H.S.; Cho, S.M.; Cha, J.G. Therapeutic effects of the forest-healing program on alcohol dependance patients and their families. Korean J. Psychol. 2008, 13, 727-743. [CrossRef]

36. Zuckerman, M. Development of a situation-specific trait-state test for the prediction and measurement of affective responses. $J$. Consult Clin. Psychol. 1977, 45, 513-523. [CrossRef] 
37. Lee, D.G.; Park, B.J. Effects of elevated public sky garden on employees' psychological restoration-A case study of Seoullo 7017. J. East Asian Landscape Stud. 2018, 12, 51-60.

38. Lee, K.A.; Hicks, G.; Nino-Murcia, G. Validity and reliability of a scale to assess fatigue. Psychiatry Res. 1991, 36, 291-298. [CrossRef]

39. Kim, H.R. Fatigue and its related factors in patients on hemodialysis. J. Korean Acad. Nurs. 1996, 26, 53-72. [CrossRef]

40. Kim, M.J.; Park, C.N.; Kang, Y.E.; Lee, S.S. The effects of nutrition education and regular exercise on nutritional status, quality of life and fatigue in hemodialysis patients. J. Korean Diet. Assoc. 2013, 19, 373-388. [CrossRef]

41. Kim, J.H. Effect of Guided Imagery Applied to Hemodialysis Patients. Ph.D. Thesis, Seoul National University, Seoul, Korea, 1995.

42. Choi, E.Y.; Lee, H.Y. Prediction model of fatigue for hemodialysis patients. In Proceedings of the 5th International Nursing Conference, Seoul, Korea, 19-21 October 2005; p. 228.

43. Park, S.O. A study on the long-term hemodialysis patient's hypotension and prevention from blood loss in coil during the hemodialysis. J. Korean Acad. Nurs. 1981, 11, 83-104.

44. Hwang, S.H.; Park, J.K. The stress-buffering effect of natural environment on the job-seeking of the students-focused on savanna theory-. Tour. Res. 2009, 24, 85-102.

45. Yi, Y.K. Restorative effects of natural landscape on university students' stress reduction and cognitive enhancement. J. Korean Inst. Landsc. Archit. 2015, 43, 127-137. [CrossRef]

46. Kim, J.Y.; Shin, C.S.; Lee, J.K. The effects of forest healing program on mental health and melatonin of the elderly in the urban forest. J. People Plants Environ. 2017, 20, 95-106. [CrossRef]

47. Choi, K.M.; Shin, W.S.; Yeoun, P.S.; Cho, Y.M. Effect of forest waking exercise on university student, stress and fatigue. J. Korean Inst. For. Recreat. 2011, 15, 61-66. [CrossRef]

48. Park, B.J.; Miyazaki, Y. Physiological Effects of Viewing Forest Landscapes: Results of field tests in Atsugi city, Japan. J. Korean For. Soc. 2008, 97, 634-640.

49. Alvarsson, J.J.; Wiens, S.; Nilsson, M.E. Stress recovery during exposure to nature sound and environmental noise. Int. J. Environ. Res. Public Health 2010, 7, 1036-1046. [CrossRef] [PubMed]

50. Igarashi, M.; Yamamoto, T.; Lee, J.; Song, C.; Ikei, H.; Miyazaki, Y. Effects of stimulation by three-dimensional natural images on prefrontal cortex and autonomic nerve activity: A comparison with stimulation using two-dimensional images. Cogn. Process. 2014, 15, 551-556. [CrossRef]

51. Ikei, H.; Song, C.; Miyazaki, Y. Physiological effects of touching coated wood. Int. J. Environ. Res. Public Health 2017, 14, 0773. [CrossRef] [PubMed]

52. Jo, H.; Song, C.; Ikei, H.; Enomoto, S.; Kobayashi, H.; Miyazaki, Y. Physiological and psychological effects of forest and urban sounds using high-resolution sound sources. Int. J. Environ. Res. Public Health 2019, 16, 2649. [CrossRef] [PubMed]

53. Vinik, A.I.; Ziegler, D. Diabetic cardiovascular autonomic neuropathy. Circulation 2007, 115, 387-397. [CrossRef]

54. Black, P.H. Central nervous system-immune system interactions: Psychoneuroendocrinology of stress and its immune consequences. J. Antimicrob. Agents Chemother. 1994, 38, 1-6. [CrossRef]

55. Lee, M.O.; Shin, C.S.; Yeon, P.S.; Shin, M.J.; Lee, J.S.; Choi, J.H. The effects of forest-walking exercise on NK cells and blood melatonin levels of women in Their 50s. J. Korean Inst. For. Recreat. 2017, 21, 39-52. [CrossRef]

56. Lyu, B.; Zeng, C.; Xie, S.; Li, D.; Lin, W.; Li, N.; Jiang, M.; Liu, S.; Chen, Q. Benefits of a three-day bamboo forest therapy session on the psychophysiology and immune system responses of male college students. Int. J. Environ. Res. Public Health 2019, 16, 4991. [CrossRef]

57. Park, H.G.; Na, H.Y. Natural killer cell activity of peripheral blood in hemodialyzed patients. J. Busan Med Univ. 1995, 35, 93-102.

58. Philippe, Z.; Raymond, M.H. Natural killer-cell function in hemodialysis patients: Effect of the dialysis membrane. Kidney Int. 1993, 43, 1298-1305. [CrossRef]

59. Liszka, M.; Zukowska, S.E.; Grzeszczak, W.; Moczulski, D.; Religa, Z. Natural killer cell count in hemodialysis patients. Pol. Arch. Med. Wewn. 1998, 100, 9-18. [PubMed]

60. Dhima, X.; Jaku, G.; Zefaj, D.; Ioannis, K.; Chrysoula, V.; Margitsa, S.; Maria, P. Needs of Hemodialysis Patients and Factors Affecting Them. Glob. J. Health Sci. 2015, 8, 109-120. [CrossRef]

61. Krzysztof, L.; Zbigniew, N.; Stanisław, N. Age-related differences in the quality of life in end-stage renal disease in patients enrolled in hemodialysis or continuous peritoneal dialysis. Med. Sci. Monit. 2013, 19, 378-385. [CrossRef] 